Article

\title{
Urban Ecosystem Vulnerability Assessment of Support Climate-Resilient City Development
}

\author{
Zipan Cai ${ }^{1}$, Jessica Page ${ }^{2, *}$ and Vladimir Cvetkovic ${ }^{1}$ \\ ${ }^{1}$ Department of Sustainable Development, Environmental Science and Engineering, KTH Royal Institute of Technology, \\ Sweden; E-Mails: zipan@kth.se (Z.C.), vdc@kth.se (V.C.) \\ 2 Department of Physical Geography, Stockholm University, Sweden; E-Mail: jessica.page@natgeo.su.se \\ * Corresponding author
}

Submitted: 19 February 2021 | Accepted: 28 April 2021 | Published: 19 August 2021

\begin{abstract}
Climate change poses a threat to cities. Geospatial information and communication technology (Geo-ICT) assisted planning is increasingly being utilised to foster urban sustainability and adaptability to climate change. To fill the theoretical and practical gaps of urban adaptive planning and Geo-ICT implementation, this article presents an urban ecosystem vulnerability assessment approach using integrated socio-ecological modelling. The application of the Geo-ICT method is demonstrated in a specific case study of climate-resilient city development in Nanjing (China), aiming at helping city decision-makers understand the general geographic data processing and policy revision processes in response to hypothetical future disruptions and pressures on urban social, economic, and environmental systems. Ideally, the conceptual framework of the climate-resilient city transition proposed in this study effectively integrates the geographic data analysis, policy modification, and participatory planning. In the process of model building, we put forward the index system of urban ecosystem vulnerability assessment and use the assessment result as input data for the socio-ecological model. As a result, the model reveals the interaction processes of local land use, economy, and environment, further generating an evolving state of future land use in the studied city. The findings of this study demonstrate that socio-ecological modelling can provide guidance in adjusting the human-land interaction and climate-resilient city development from the perspective of macro policy. The decision support using urban ecosystem vulnerability assessment and quantitative system modelling can be useful for urban development under a variety of environmental change scenarios.
\end{abstract}

\section{Keywords}

climate change; climate-resilient city; ecosystem vulnerability; Geo-ICT; socio-ecological model

\section{Issue}

This article is part of the issue "Smart Urban Governance for Climate Change Adaptation" edited by Thomas Thaler (University of Natural Resources and Life Sciences, Austria), Patrick Witte (Utrecht University, The Netherlands), Thomas Hartmann (TU Dortmund University, Germany) and Stan Geertman (Utrecht University, The Netherlands).

(C) 2021 by the authors; licensee Cogitatio (Lisbon, Portugal). This article is licensed under a Creative Commons Attribution 4.0 International License (CC BY).

\section{Introduction}

Climate change places increasing stress on the built environments of cities in the new era, bringing challenges to urban planning and development as well as urban services and management systems (Carter et al., 2015; Wamsler et al., 2013). Climate change impacts on cities, some of which are already being seen, include more frequent droughts, flooding, and other extreme weather events, flooding due to rising sea levels, and increasing temperatures and heat waves (worsened in cities due to urban heat island effects; Abiodun et al., 2017; Deilami et al., 2018; Fu et al., 2017). As socio-economic and ecological integrated systems, cities are likely to be subject to increasing disruptions due to climate change (Jabareen, 2013). The main reason is that the system integration is vulnerable and its self-regulation capacity is relatively weak and easily affected by the changes 
of external factors (Carmin et al., 2009). The challenge then is to better focus on human activities to cope with and minimise urban climate and environmental change impacts.

Because there are no international protocols on climate adaptation planning at the local level, and most national governments do not work together to address potential threats, some cities are developing independent goals and actions to jumpstart adaptive city development (Carmin et al., 2012; Roberts et al., 2011). Developing cities to be more climate-resilient is an increasing and pioneering effort jointly with actions to mitigate climate change (Dolman, 2021; Hofstad \& Torfing, 2017). With the means of geospatial information and communication technology (Geo-ICT), some climateresilient labelled cities have made progress in implementing timely responses to climate disasters, risk assessment of infrastructure, and coordination of urban planning and management (Aina, 2017; Mejri et al., 2017). Geo-ICT generally combines geographic information and ICT as a planning support system that facilitates efficient and effective governance, for example, through improving master planning, coordination, and cooperation (Meera et al., 2012). It includes the geographic information system (GIS), the spatial database management system, spatial information infrastructures, spatial decision support systems, and other geospatial technologies.

Verweij et al. (2020) presented a participatory method-QUICKScan-which promotes participatory use and transformation of geographic data to help stakeholders and decision-makers understand the humanland causality. Navarra and Bianchi (2013) proposed a cadastral system in which the operating process consists of a land management paradigm, Geo-ICT, and spatially enabled government to reduce greenhouse gas emissions (GHG), and further create sustainable urban governance dynamics. Pan et al. (2020) used a planning support system to model future land-use change and the related GHG to suggest spatial planning and policy changes that could significantly reduce the increase in GHG emissions associated with urban expansion to accommodate a growing population. Aina (2017) suggested a visual geographic information data platform to monitor the sustainability of cities' green facilities and the corresponding policy effects, aiming to create smart city development in Saudi Arabia. Hay et al. (2010) used the heat map overlay method to assess regional energy consumption and efficiency, allowing city planners and decision-makers to coordinate energy allocation and facility planning. The methods mentioned in all these and many other similar studies can be summarised into three groups of methods: tool-based planning regulation, risk reduction, and problem retreatment. Although one or more of these methods have similar principles and mechanisms and apply to solving the problems of local human settlements, the degree to which they are integrated into the overall urban planning is disparate and limited. Typical studies put forward the systematic problem-oriented approach based on Geo-ICT for the existing environmental problems but generally fail to translate the value of geographical data of various public sectors into feasible and specific planning schemes.

What can motivate city policymakers to plan for environment adaptation? Can intervention and effective incentives enhance stakeholders' participation in urban planning and policy? In this article, we describe a Geo-ICT-based socio-ecological model to enhance our understanding of the dynamic assessment of urban ecological vulnerability and the development possibilities of climate-resilient cities. To tackle specific local environmental and developmental issues, we used a city case study to quantitatively consider the prerequisites of environmentally adaptive planning and assess the feasibility of future urban growth. In the following sections, we discuss a dynamic socio-ecological model with a comprehensive assessment mechanism for urban ecosystem vulnerability and present a case study of the city of Nanjing (China) to support climate adaptation planning and the development of climate-resilient cities.

\section{Methods}

\subsection{Geo-ICT for Climate-Resilient City Transition}

Policy constraints and guidance for urban transformation and planning are complex, and policymakers need to take into account the impact of economic, social, natural, and spatial factors (Wardekker et al., 2020). The commitment to building a climate-resilient city requires a holistic operational approach (Lomba-Fernández et al., 2019). Therefore, we established a conceptual framework to answer major urban planning questions in a forwardlooking way. Inspired by Jabareen (2009), and combined with the proposed technical processing means, we divided the Geo-ICT-assisted city transition into four steps and extracted the main concepts of the four parts, illustrated in the conceptual framework shown in Figure 1. According to our understanding, these four parts are related to each other and have a sequential relationship. The conceptual elements in each part are not only the interpretation and collection of the concepts of their respective parts but also the sub-concepts of the climate-resilient city transition.

The framework starts with urban governance and planning, as it is the primary element of city transition and a way to help meet the vision of a sustainable future. Early planning decisions can involve participation, open dialogue, and collaboration between actors, including government personnel, social groups, community and civil society organisations, and other local stakeholders. Discussions on the thematic planning scheme will be conducted in the direction of climate adaptation and future sustainability. The concrete implementation of these two objectives requires a deep understanding of the existing urban environmental and ecological problems. Therefore, in the second step, we use the method 


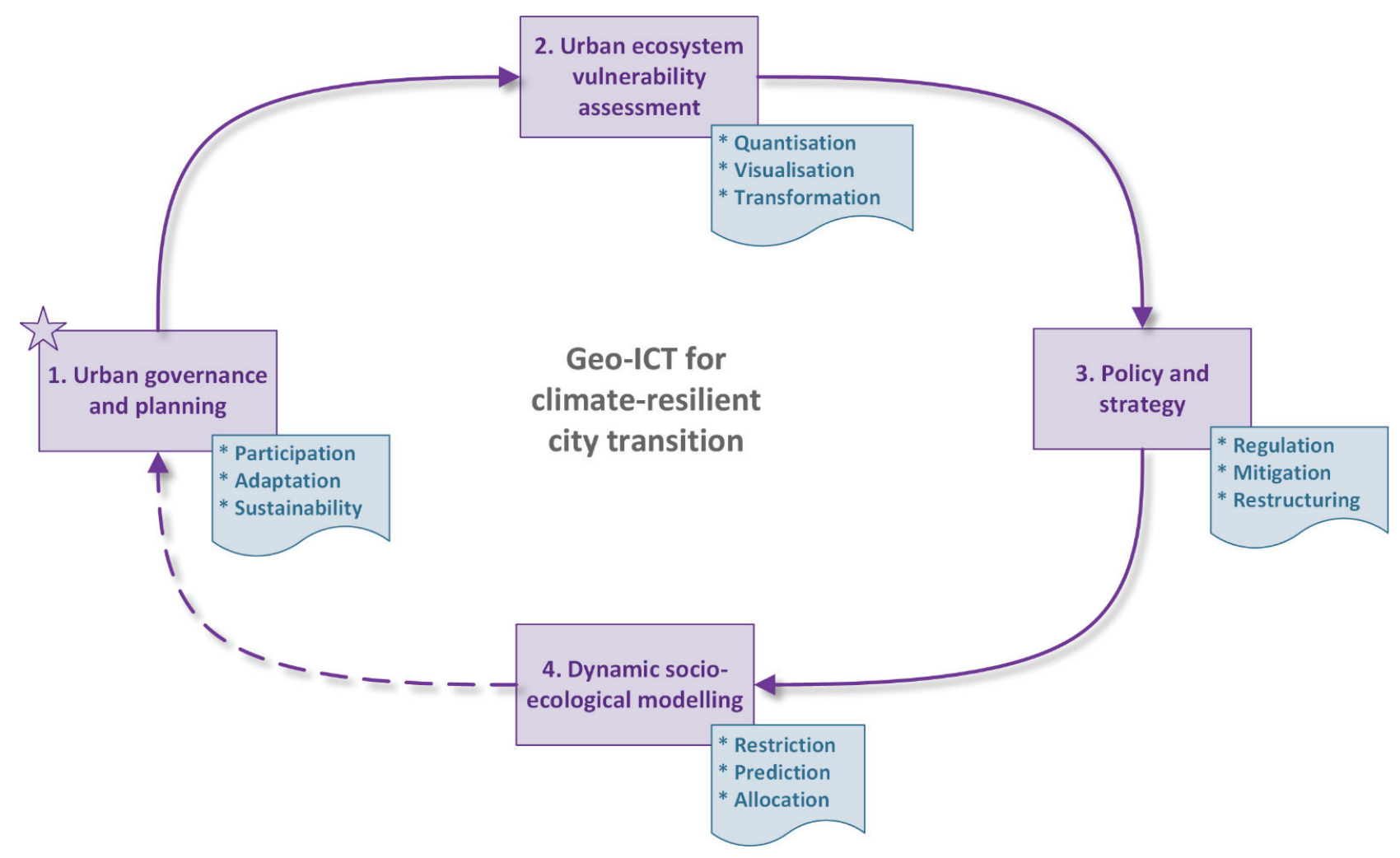

Figure 1. Conceptual framework of Geo-ICT for climate-resilient city transition.

of urban ecosystem vulnerability assessment to quantify and visualise the status quo of existing problems. We transform the results of the research data on urban ecosystem vulnerability into policy and strategic guidance information, aiming to make more integrated, deliberative, and balanced urban planning in terms of socioeconomic and ecological development. In the third step, urban decision-makers can formulate binding policies on development for areas with fragile urban ecosystems, which can be through development regulation, environmental problem mitigation, or the restructuring of existing policy and strategy. To be more specific, according to the assessment results of urban ecosystem vulnerability, policy responses can be made to set up mandatory restricted construction areas or areas with high development priority, which can pave the way for the urban expansion simulation in the next step. In the fourth and the most critical step, we use the dynamic socioecological model to predict the future size, scale, and shape of cities to aid smart city planning. The detailed restriction policies of location development in the previous step will act as a decisive factor that shapes development possibilities and affects urban land allocation for future urban development and expansion. The dynamic socio-ecological model converts the assessment results of urban ecosystem vulnerability assessment into input data and combines a series of land-use change factors to generate future urban planning schemes. As a result, simulation outputs will be provided to urban decisionmakers and all stakeholders for further discussion and guidance that connects back to the first step. Compared with the traditional urban planning guided by static ecological environment data analysis, this Geo-ICT planning support model with dynamic prediction and cyclic progressive optimisation provides decision-makers with more accurate assessment information.

\subsection{Study Area and Data}

Nanjing has the highest population density and is one of the largest $\left(6598 \mathrm{~km}^{2}\right)$ and fastest urbanising cities on the southeast coast of China (see Figure 2). Studies show that the annual average temperature and precipitation in Nanjing have been continuously increasing while sunshine duration has been decreasing in the past 50 years (Li et al., 2018). The contradiction between human and land has gradually exposed the urban system to serious environmental problems in the region, including the urban heat island effect, flood disasters, water pollution, and so on (Gu et al., 2011). In response to the "Man and the Biosphere" program initiated by UNESCO, the city proposed to build a climate-resilient city to solve these ecological and environmental problems in the face of climate change (Ji et al., 2007). This strategic thinking was also reflected in the latest round of Nanjing's master planning schemes, in which urban planners try to adjust the land use planning to seek a more scientific and reasonable land development mode to adapt to climate change. Among them, the core planning programs, such as controlling the spread of construction land, ensuring 
the security of ecological patterns, and resisting the risk of natural disasters, are all carried out in the key analysis directions of urban environmental carrying capacity, ecological environmental sensitivity, and spatial development suitability (Qi \& Gu, 2011). Taking Nanjing city as the focus area, this study not only caters to the local planning strategies guided by local policies but also further explores the feasibility and applicability of the Geo-ICT assisted planning model established.

The research data for this study includes local socioeconomic data and ecological-environmental data of Nanjing city. Taking the dynamic socio-ecological model input as the standard, we also prepared the land use and land cover data of Nanjing in 2015 as the base year. We retrieved these geographical data from the Yangtze River Delta Science Data Centre (2019), the National Earth System Science Data Infrastructure and the National Science and Technology Infrastructure of China (2020), and the National Bureau of Statistics of China (2020). The detailed format and description of all the data are attached in Table 1 in the Supplementary File. Related data pre-processing including image editing, format conversion, coordinate system unification, and other operations are completed in the preliminary work of this study.

\subsection{Urban Ecosystem Vulnerability Assessment}

As for the assessment system of ecosystem vulnerability, different scholars and researchers have different professional experience, research priorities, and perspectives, thus no consensus has yet been reached. However, the index system in academic research can be roughly divided into a single type of regional index and a comprehensive index. From the perspective of general definition, urban ecosystem vulnerability corresponds to the stability of the ecological environment, which is the variation of ecological environment in a specific spatial region driven by natural or human activities; such change is often detrimental to human survival and development (Song et al., 2010; X. Zhang et al., 2017). Therefore, when dealing with the urban ecosystem vulnerability assessment, we need to not only consider the internal function and environmental structure but also the connection between the environment and the socio-economic dimension, which requires a relatively comprehensive index system. Considering the ecological environment characteristics, the regional scale of the study area, and the local geographic data availability while referring to the existing correlation study results of the natural ecosystem and urban system, we adopted the "Sensitivity-Pressure-Elasticity" index system (Qiao et al., 2008). Among them, ecological sensitivity refers to the degree of sensitivity of the ecological environment to external natural factors and disturbances caused by perceived factors, reflecting the ability of the urban ecosystem to resist external disturbances. Ecological pressure refers to the pressure brought by natural disasters, human needs, and social and economic development to the ecological environment. Ecological elasticity refers to the ability of the ecosystem to self-adjust and recover to its original state under the premise that external disturbance or pressure does not exceed the elastic limit. Given the above, we constructed the following ecosystem vulnerability index (EVI) structure (see Table 1).
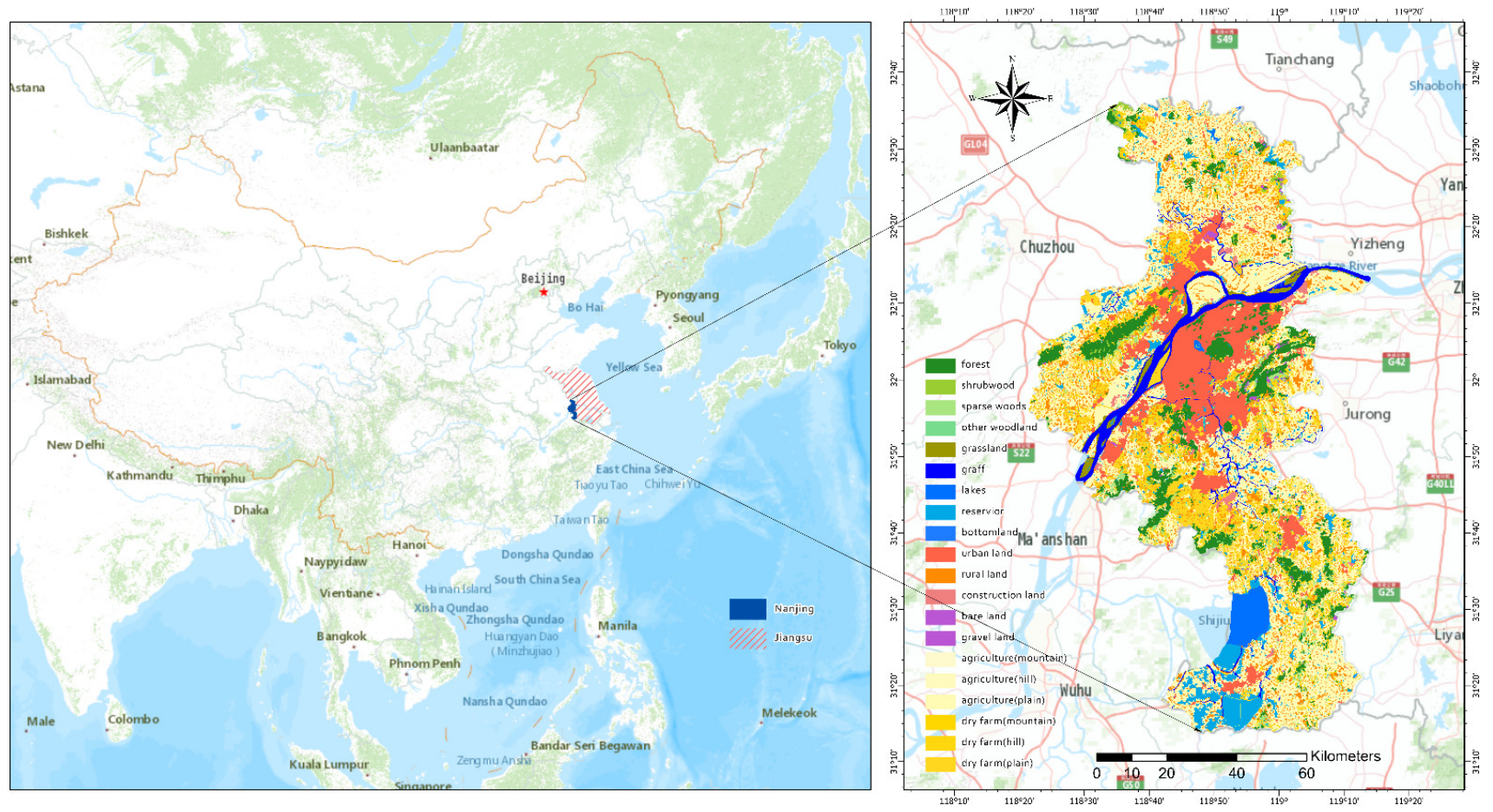

Figure 2. Location and map of Nanjing (China). 
Table 1. Index system for urban ecosystem vulnerability assessment in Nanjing.

\begin{tabular}{|c|c|c|c|}
\hline Primary index & Secondary index & Tertiary index & Calculation method description of the tertiary index \\
\hline \multirow{9}{*}{$\begin{array}{l}\text { Ecosystem } \\
\text { vulnerability } \\
\text { index (EVI) }\end{array}$} & \multirow{3}{*}{$\begin{array}{l}\text { Ecological } \\
\text { sensitivity } \\
\text { index (ESI) }\end{array}$} & X1: Degree of soil erosion & $\begin{array}{l}\text { Calculated by the equation of soil and water loss } \\
\text { (Wan et al., 2006) }\end{array}$ \\
\hline & & $\mathrm{X} 2$ : Terrain factor & $\begin{array}{l}\text { Calculated by the digital elevation model index } \\
\text { conversion }\end{array}$ \\
\hline & & X3: Landscape sensitivity & $\begin{array}{l}\text { Degree of landscape convergence and richness } \\
\text { (Fu et al., 2017) }\end{array}$ \\
\hline & \multirow{3}{*}{$\begin{array}{l}\text { Ecological } \\
\text { pressure } \\
\text { index (EPI) }\end{array}$} & X4: Construction pressure & $\begin{array}{l}\text { Ratio of construction land per square kilometre } \\
\text { (Han et al., 2016) }\end{array}$ \\
\hline & & X5: Population pressure & Standardised population density \\
\hline & & X6: Economic pressure & Standardised volume level of GDP \\
\hline & \multirow{3}{*}{$\begin{array}{l}\text { Ecological } \\
\text { elasticity } \\
\text { index (EEI) }\end{array}$} & X7: Vegetation productivity & Normalised difference vegetation index \\
\hline & & X8: Nature protection factor & $\begin{array}{l}\text { Standardised importance level value of nature } \\
\text { reserves }\end{array}$ \\
\hline & & $\begin{array}{l}\text { X9: Regional environmental } \\
\text { suitability }\end{array}$ & $\begin{array}{l}\text { Principle multi-criteria assessment on the data of } \\
\text { annual average precipitation, temperature, and } \\
\text { water distribution (Jafari \& Zaredar, 2010) }\end{array}$ \\
\hline
\end{tabular}

Note: The importance level of nature reserves is retrieved from "Regulations of the People's Republic of China on Nature Reserves" (National Earth System Science Data Infrastructure \& National Science and Technology Infrastructure of China, 2020), and it includes national and regional protection areas.

To synthesise the calculation of the urban EVI, we suggest the three-helix assessment model, which is a comprehensive evaluation suitable for the compromised relationship among ecological sensitivity, pressure, and elasticity of the "society-nature" coupled system. The calculation formula is as follows (Hong et al., 2016):

$$
\begin{aligned}
E V I= & f(E S I, E P I, E E I)=\sum_{x=1}^{n}\left(E S I_{x} \times w_{s}\right) \\
& +\sum_{x=1}^{n}\left(E P I_{x} \times w_{P}\right)+\sum_{x=1}^{n}\left(E E I_{x} \times w_{E}\right)
\end{aligned}
$$

where $E S I_{x}, E P I_{x}, E E I_{x}$ are respectively the ESI, EPI, and EEI of each cell in raster data while $w_{s}, w_{P}, w_{E}$ are the weights of the three indexes respectively. Since each calculated space vector needs to be weighted to carry out multivariate statistics, we use the spatial principal component analysis method in the GIS spatial analysis module (Rahman et al., 2015). This geoprocessing method calculates the principal component of space and its contribution rate, using the formula:

$$
\begin{gathered}
F=\sum_{i=1}^{m} F_{i} \times \frac{V_{i}}{\sum_{i=1}^{m} V_{i}} \\
w_{j}=\sum_{i=1}^{m}\left(\frac{b_{i j}}{\sqrt{x_{j}}} \times \frac{\sqrt{Y_{i}}}{\sum_{i=1}^{m} V_{i}}\right) / \sum_{j=1}^{n} \sum_{i=1}^{m}\left(\frac{b_{i j}}{\sqrt{x_{j}}} \times \frac{\sqrt{V_{i}}}{\sum_{i=1}^{m} V_{i}}\right)
\end{gathered}
$$

where $F$ is the overall (global) index, $F_{i}$ is the $i^{\text {th }}$ principal component for spatial principal component analysis, $m$ is the number of components, $\gamma_{i}$ is the characteristic vector value of the $i^{\text {th }}$ principal component, $w_{j}$ is the weight of the $j^{\text {th }}$ index, $n$ is the number of indices, $\sqrt{X_{j}}$ is the standard deviation of the $j^{\text {th }}$ index, and $b_{i j}$ is the load coefficient of the $i^{\text {th }}$ principal component on the $j^{\text {th }}$ index. Thus, the secondary index in equation (1) and their weights can be calculated using equations (2) and (3).

In addition, we also need to consider the positive and negative correlation between the secondary index and the primary index. Therefore, we conduct data standardisation processing before calculation:

$$
\begin{aligned}
& \text { For positive index: } P_{f}=\left(P-P_{\min }\right) /\left(P_{\max }-P_{\min }\right) \\
& \text { For negative index: } P_{f}=\left(P_{\max }-P\right) /\left(P_{\max }-P_{\min }\right)
\end{aligned}
$$

where $P_{f}$ is the index standardisation value, $P$ is the original value, and $P_{\max }$ is the maximum index value while $P_{\min }$ is the minimum index value. In the proposed index system, ESI and EPI are positive correlation indices while $\mathrm{EEI}$ is a negative correlation index.

\subsection{Dynamic Socio-Ecological Modelling}

In order to generate results of a phased policy that relates to dynamic urban development, we established a LEAM-based socio-ecological model, which supports the input of urban ecosystem vulnerability as a constraint for future land development. LEAM stands for the land-use evolution and impact assessment model, which is a smart planning support tool for urban dynamic spatial simulation. LEAM is a spatial model which predicts the future development locations in a study area with fine-scale $(30 \times 30 \mathrm{~m})$ gridded output maps (Deal et al., 2013; Deal \& Pallathucheril, 2008; Pan et al., 2018). 
This modelling tool was originally developed for use in Illinois, USA, and has been adapted in this work for use in Nanjing. Some of the latest studies with the LEAM model indicate that the model is suitable for visualisation, quantitative, and data transformation support (Cai et al., 2020; Pan et al., 2019; L. Zhang et al., 2021). Similar to the operational theory of cellular automata, LEAM consists of a simulation environment in a grid space where the cell properties would be transformed according to defined transformation rules and vicinities. Before the establishment of cell transformation rules, a set of initial drivers and projections will be imported as referenced factors for the land-use change simulation. The drivers cover both physical geographical (water, soil, slope, and other landforms) and socio-economic aspects (residence, employment, road network, administrative boundaries, and other planning areas). The urban land-use change drivers indicate the complex interaction between the urban system and the surrounding environment. All of the factors combine and interact in a variety of ways in the model to assign probabilities of potential land-use changes to each $30 \times 30 \mathrm{~m}$ cell in the studied grid space. The distribution of these urban built-up land change probability values is the result of the general superposition of local and global effects. It includes causal change mechanisms, such as the accessibility of cells to city attractors, the constraints of the ecological environment, the social-economic impact, and the stochastic disturbance. Among them, we extract the urban ecosystem vulnerability assessment result as the constraints on growth and consider zoning effects on urban land expansion. The change possibility of each land-use cell from urban unbuilt-up area to built-up area is defined as:

$$
P_{i, t}=\alpha\left(A_{i, t}+N\left(\theta_{i, t-1}\right)\right) f\left(R_{i, t}\right)
$$

where $P_{i, t}$ is the land-use change probability for land-use cell $i$ at time step t, $\alpha$ is a stochastic disturbance parameter that facilitates the generated patterns to be closer to reality, $f\left(R_{i, t}\right)$ is the function of multiple growth restrictions and planning zoning effects on land-use types for land-use cell $i$ at time step $t$, and $A_{i, t}$ is the accessibility value for land-use cell $i$ at time step $t$, and is defined as:

$$
A_{i, t}=\frac{\sum_{j=1}^{n} a_{i, j} w_{i, j}}{n}
$$

where $a_{i, j}$ is the attraction power of land-use cell $i$ to urban attractor cell $j$ while $w_{i, j}$ is the corresponding weight and $n$ is the total number of the attractors.

We aim to quantify how urban built-up areas are shaped by location-choice factors including population and employment centres, highways and major streets, forest and water resources, and compare the agglomeration and dispersion of developed lands in different urban areas. The location-choice factors are defined as attractors in this study under the assumption that they determine the surrounding development in a gravitytype function in which the attraction power decays with increased distances. This gravity function can be determined through the shortest distance algorithm and data value from various sources. This study uses Pan et al.'s (2018) parallel stochastic greedy algorithm to find the shortest distance and the inverse distance model to determine the attraction value for population, employment, and transportation attractors. In this inverse model, for each attractor $j$, its attraction to landuse cell $i$ is noted as $a_{i, j}$ and is calculated as:

$$
a_{i, j}=\sum_{k \in S_{j}} \frac{p_{k}}{d_{i j}}
$$

where $S_{k}$ is the set of attractors of type $j, p_{k}$ is the attraction value of the $k_{t h}$ attractor in $S_{k}, d_{i j}$ is the distance between the $k_{t h}$ attractor in $S_{k}$, and land-use cell $i$ is calculated by stochastic greedy algorithm.

In addition, $N\left(\theta_{i, t-1}\right)$ in formula (1) is the function that converts the nearest neighbouring effects to a probability value and is defined as:

$$
N\left(\theta_{i, t-1}\right)=\frac{\sum_{1}^{k}\left(N_{p r, t-1}+\sigma_{i}\right)}{k}
$$

where $N_{p r, t-1}$ is the development possibility for neighbourhood cells in time step $t-1$ while $\sigma_{i}$ is a spread coefficient over all surrounding cells $(k \leq 8)$.

In the LEAM model, land-use transformation potential cells are assessed by explicit quantification drivers which contribute to the urban land-use change. The causal mechanisms involved in knowledge change provide local decision-makers with the opportunity to test policy and investment decisions that are key components of the scenario planning exercise and are different from the traditional static geographic data analysis led by the specific planning. The accessibility approach based on formula (7) is used to measure the current land-use cells of cities and population centres to help identify areas where re-development of existing developed land is highly likely. The probability mapping of future urban land-use development (calculated by formula 6 ) is based on model calibration and scenario setting. The details on model calibration, validation, and parameter tuning can be found in Appendix B in the Supplementary File.

\section{Results and Discussions}

\subsection{Urban Ecosystem Vulnerability Assessment Results}

According to the defined equation of the urban EVI (in Section 2.3), we used the raster calculator and the band arithmetic tool in ArcGIS Pro to generate the evaluation result for Nanjing (see Figure 3). The standardised data results of three sub-indexes ESI, EPI, and EEI are also attached in Figure 4. Based on the distribution of EVI results, we assigned five evaluation grades based on the index range (equal interval) and calculated the area proportion of each index grade as shown in Table 2. By summarising the information in the figure and table, we can see that the spatial heterogeneity of ESI, EPI, and 
EEl in the study area is high, and the ecological sensitivity, pressure, and elasticity of each region are different. Among them, the area of very low sensitivity ESI in the study area accounted for the largest proportion$78.6 \%$ - which is mainly distributed in the north and south along the river plain. On the contrary, the EPI result shows the characteristics of urban agglomeration and distribution because it is related to human social activities. It occupies the highest proportion in areas with very high-pressure-62.5\% - while the main land use in these areas is urban built-up land and farmland area. From the EEI result, areas with the highest area ratios are moderate and high $-36.4 \%$ and $35.2 \%$ respectively. The areas involved are mostly urban built-up land, and the junction and boundary of urban built-up land, farmland, and grassland. When the results of the three sub-indices were added into the range method and weighted, we obtained the EVI with a completely different evaluation grading and distribution result. The EVI values of moderate-, low-, and high-grade areas were basically the same, and accounted for the highest proportion. These areas are mainly distributed along the urban development boundaries. Also, some highly ecosystem-sensitive areas are distributed in the special terrain and landforms. For example, steep mountain areas are prone to ecological risks of soil and water loss while water sources and wetlands near the Yangtze River are susceptible to flood disasters. In general, the distribution of low ecosystem vulnerability areas presents an increasing "circle-layer" distribution from the urban centre to the areas where green space is more concentrated. The existing urban land is mostly distributed in plain regions, where the intensity of land development is high and the vegetation is scarce. The ecosystem vulnerability of urban land represented by the central urban area and the adjacent suburban areas is high. However, the areas with moderate EVI have a relatively better ecological environment, stronger ecological anti-disturbance ability, and better

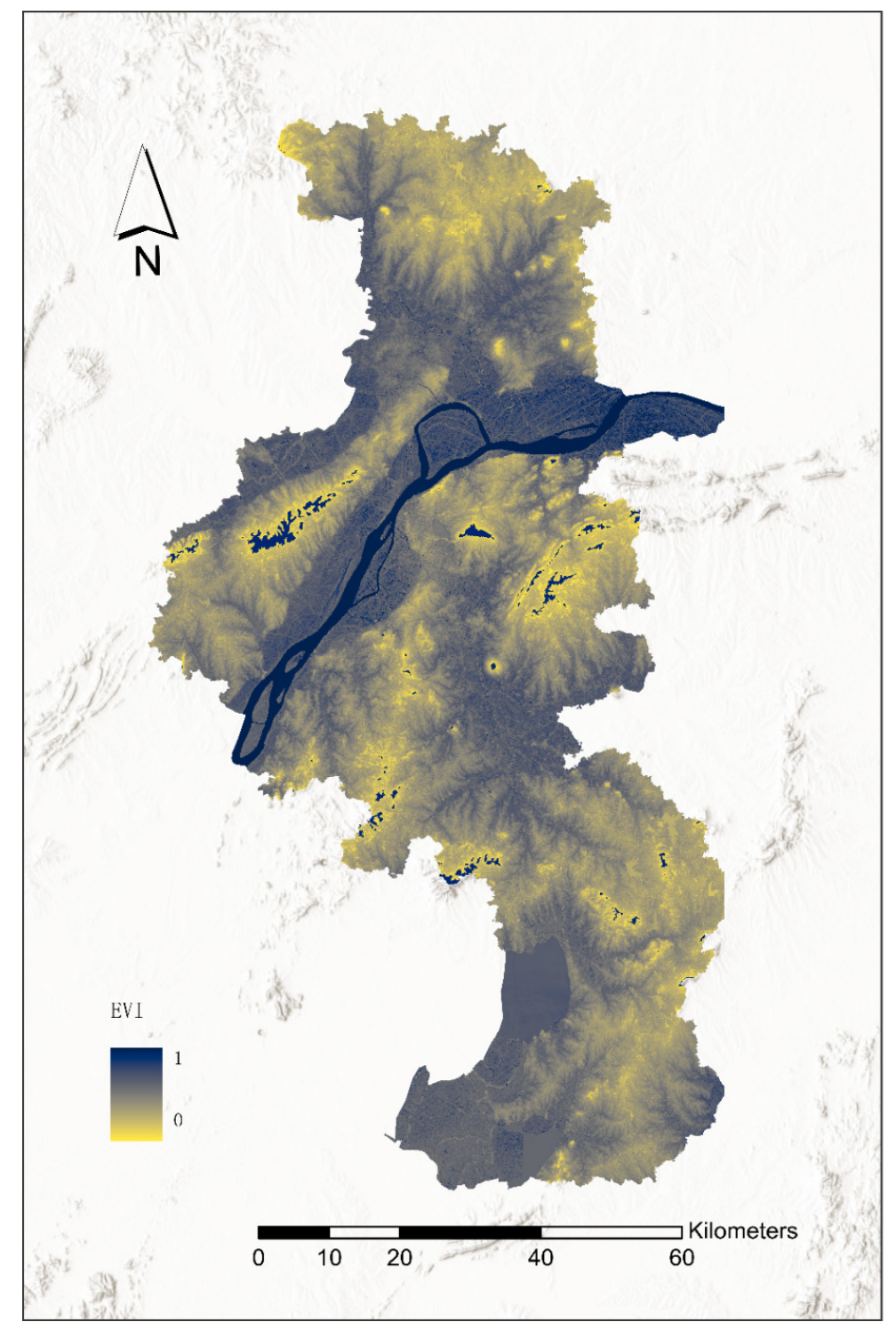

Figure 3. Urban EVI in Nanjing. 


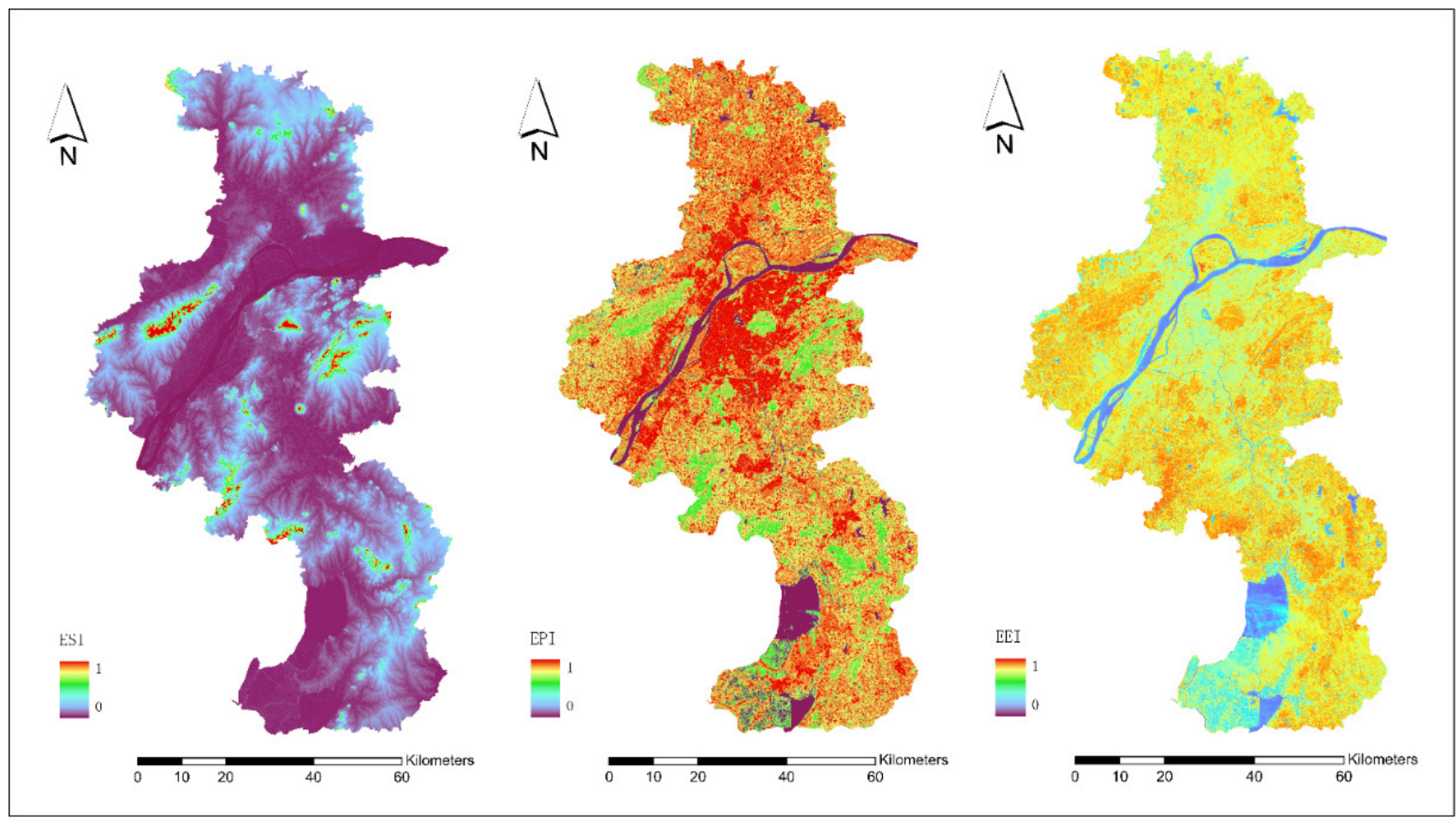

Figure 4. Standardised data results of three sub-indexes of ecosystem vulnerability in Nanjing.

disaster recovery ability. Ideally, these areas with low urban ecosystem vulnerability would be the preferred areas for future urban land development, regardless of other economic and social factors.

There is a close relationship between land use and land cover patterns and urban ecosystem vulnerability. The dominant factor of urban ecosystem vulnerability is the change of land use and land cover during urbanisation, that is, the transformation of natural vegetation to arable land or from arable land to urban construction land. Apart from rivers, lakes, and steep mountain landforms, urban construction land is the most vulnerable type of land use. The northern and southern suburban areas are mainly faced with the risk of cultivated land loss and landscape fragmentation and are also the main distribution areas of medium and high vulnerability. The ecosystem vulnerability of grassland forest areas in the plain is low, but it has a certain risk of soil erosion.

\subsection{Dynamic Socio-Ecological Modelling Results}

Although the results of the urban ecosystem vulnerability assessment guide the direction of future urban development in a certain sense, the specific development still needs to follow the basic driving mechanism of urban land-use change (Chen et al., 2016). Therefore, in the socio-ecological model, we set $\mathrm{EVI}$ values between 0 and 1 in advance and regard it as an important part of the possibility of urban land-use change (see Equation 6). The area with an EVI of 1 was defined as the restricted construction area to keep the most vulnerable areas from further development. As a result, we obtained the final simulated urban built-up land in 2040 in Nanjing through the established dynamic socio-ecological model (see Figure 5). It can be noted that the future urban built-up land area in 2040 mainly expands outward from the existing urban land agglomeration areas and are

Table 2. The area proportion of the primary and secondary index of urban ecosystem vulnerability in each evaluation grade of Nanjing city.

\begin{tabular}{|c|c|c|c|c|c|}
\hline \multirow[b]{2}{*}{ Evaluation grade } & \multirow[b]{2}{*}{ Range of index } & \multicolumn{4}{|c|}{ Area proportion (\%) } \\
\hline & & EVI & ESI & EPI & $\mathrm{EEI}$ \\
\hline Very low & $0-0.2$ & 13.4 & 78.6 & 4.8 & 6.2 \\
\hline Low & $0.2-0.4$ & 26.2 & 6.1 & 5.5 & 16.3 \\
\hline Moderate & $0.4-0.6$ & 26.4 & 3.2 & 12.3 & 36.4 \\
\hline High & $0.6-0.8$ & 22.7 & 6.8 & 14.9 & 35.2 \\
\hline Very high & $0.8-1$ & 11.3 & 5.3 & 62.5 & 5.9 \\
\hline
\end{tabular}

Note: The result of area proportion is derived from the proportion of the number of pixel cells in the total number of cells in each index range by ArcGIS. 


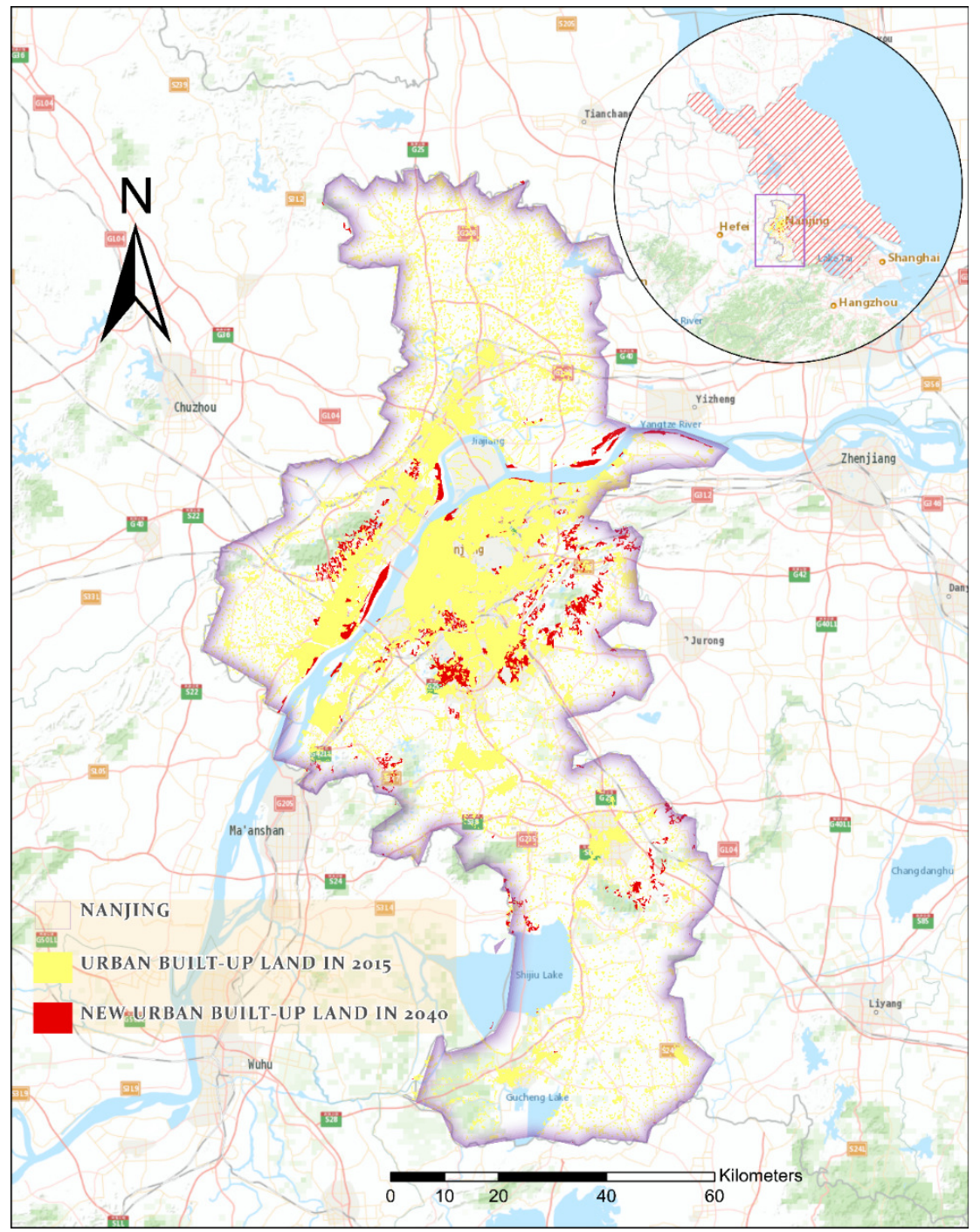

Figure 5. Prediction map of new urban built-up land in 2040 in Nanjing.

scattered and orderly around the urban built-up land in 2015. In addition to the central city area, some future urban areas are distributed in the new urban area on the north bank of the Yangtze River while a small number of areas are distributed in the suburban area in the south of the city. The predicted development results are broadly consistent with Nanjing's comprehensive plan for 2040 in the direction, area, scale, and other aspects of the growth plot. However, in terms of development details, the intensity of development in areas with fragile urban ecosystems is more emphasised in our modelling result.

\subsection{Analysis of Results to Inform Planning and Policy}

If we incorporate the periodic results of urban ecosystem vulnerability assessment and urban land growth simulation into the conceptual framework of Geo-ICT assisted climate-resilient city transition described above, we find that this is beneficial to both climate adaptation in urban planning and the future sustainable development of the city. Firstly, it is suggested to adopt dif- ferent protection and restrictive development strategies according to the results of urban ecosystem vulnerability assessment in Nanjing. For example, for the fragile mountainous areas in the northern part of the city dominated by ecological sensitivity, a conservation strategy should be adopted, such as closing mountains for forest cultivation, returning farmland to natural grasslands, and gradually restoring the damaged natural forest and grassland ecosystems. For the regions with low ecological elasticity, rational utilisation of resources should be carried out to increase the area of artificial forest, to avoid human economic activities exceeding the scope of regional ecological carrying capacity. For the urban core areas with high ecological pressure, the future development intensity needs to be limited, and ecological corridors should be further improved to increase the urban green space area. Secondly, the predicted growth urban area can be used as the recommended priority area for future planning and development, as well as the reference basis for realising and adjusting development expectations. To be more specific, it can be the rational 
adjustment of the vision of urban social and economic future development, including the distribution of population growth, employed population growth, road planning, economic growth, and so on. Lastly, the simulation results can be generated repeatedly after the development vision is updated and changed; it can even lead to secondary and in-depth participatory deliberations leading to a more socially and ecologically sound viable development scheme.

Supporting policy exploration and implementation demonstrates the applicability of the Geo-ICT assisted modelling approach. Although future urban development is faced with uncertainties, a visualisation and data-based prediction of urban growth results increases the possibility of the vision development direction to meet the multiple demands from many actors in the city. Theoretically, urban planners can adopt advanced layout and rational planning to protect the urban natural system, the built environment, and the human living environment to minimise the impact of disruptive climate change on cities and their inhabitants. In practice, the implementation of such planning is difficult and often highly dependent on local and regional conditions. However, we can always set up different EVI systems based on the local geographical characteristics to adapt to different cities and regions. Whether to adjust the model parameters and forecast time to get the simulation results expected in accordance with planning needs to be determined according to the planning scale and policy standards of different regions. Different development scenarios can even be formulated in the policy and strategy phase according to the development needs to reveal the process trends and influencing factors of urban evolution in the future.

\section{Conclusions}

This article presents a Geo-ICT approach for climateresilient city transition, which also answers the key questions about what, when, and how to guide urban policymakers in planning towards a more sustainable and climate-resilient urban development. This approach not only accounts for the imperfection of the support system in the conceptual framework of city planning but also proposes a scientific methodological guidance scheme using existing Geo-ICT-related technologies. Through a case study of Nanjing, we argue for specific types of incentives that promote institutional change and urban adaptation planning to respond to the call for climateresilient city development. Our research results provide decision support for the subjective urban development, as well as ideas for the process of universal urban adaptive planning in a broad sense.

The main findings of this study are that: i) the transformation of the periodic geographical data results of urban ecosystem vulnerability assessment into policies and strategies for sustainable development provides a methodology for the continuous revision of urban gov- ernance and planning; ii) the interaction and causality between the local environmental ecosystem and the socio-economic system simplified and summarised by the socio-ecological modelling method, can help policymakers understand the specific impacts of proactive policy interventions; and iii) the simulated future urban growth can provide a reference for urban development goals and planning schemes because it intuitively and effectively shows to what extent urban land can be developed and the priority of the development in the region at a future time. These findings not only confirm the value of Geo-ICT-assisted planning through the socioecological model construction, but also expose new possibilities for city adaptive planning and the policy-making process. Ideally, the generated information from the comprehensive modelling process is an added value of detailed planning support, which can help planners effectively collaborate, communicate, and reach consensus. Through the city-based case study, we find that as a supplement to planning experience knowledge, the Geo-ICT approach integrated multi-planning policy-making and complex model simulation methods through progressive thinking and provided a circular way of exploring potential urban development possibilities.

In practice, the transformation from the Geo-ICT modelling results into concrete implementation measures still requires a means of adapting to local conditions. We must pay attention to the results of a planning scheme that relies entirely on the Geo-ICT approach to respond quickly to ecological priority development scenarios and whether they ignore the reality of capital dominance. The extent to which economic development benefits are limited by the specific development distribution advocated, how much ecological vulnerability risks caused by climate change are avoided, and how to balance the advantages and disadvantages of multiple planning schemes need to be further explored in future studies. Furthermore, we need to explore the influence and feasibility of urban development beliefs and goals on the modelling of scientific urban development because it may lead decision-makers into a dilemma between maintaining the status quo and acting more aggressively. Therefore, in future studies, one must analyse more accurately the relationship between urban ecosystem vulnerability and the possibility of future urban development, explore the geomorphological categories of existing land plots occupied by urban growth land, and calculate the possible loss of urban ecosystem service value. In this manner, we can more strongly link practical measures to on-going activities and thereby better support planning and implementation that is adapted to specific development expectations and goals.

\section{Acknowledgments}

The authors would like to express appreciation to Prof. Deal Brian and Prof. Huang Xianjin for their valuable opinions on the initial ideas of the article. The authors 
also highly appreciate the four anonymous reviewers for providing helpful and constructive comments and suggestions.

\section{Conflict of Interests}

The authors declare no conflict of interests.

\section{Supplementary Material}

Supplementary material for this article is available online in the format provided by the authors (unedited).

\section{References}

Abiodun, B. J., Adegoke, J., Abatan, A. A., Ibe, C. A., Egbebiyi, T. S., Engelbrecht, F., \& Pinto, I. (2017). Potential impacts of climate change on extreme precipitation over four African coastal cities. Climatic Change, 143(3), 399-413.

Aina, Y. A. (2017). Achieving smart sustainable cities with GeolCT support: The Saudi evolving smart cities. Cities, 71, 49-58.

Cai, Z., Wang, B., Cong, C., \& Cvetkovic, V. (2020). Spatial dynamic modelling for urban scenario planning: A case study of Nanjing, China. Environment and Planning B: Urban Analytics and City Science, 47(8), 1380-1396.

Carmin, J., Anguelovski, I., \& Roberts, D. (2012). Urban climate adaptation in the Global South: Planning in an emerging policy domain. Journal of Planning Education and Research, 32(1), 18-32.

Carmin, J., Roberts, D., \& Anguelovski, I. (2009). Planning climate resilient cities: Early lessons from early adapters. In Proceedings of the World Bank Fifth Urban Research Symposium on Cities and Climate Change: Responding to an Urgent Agenda (pp. 5-8). World Bank.

Carter, J. G., Cavan, G., Connelly, A., Guy, S., Handley, J., \& Kazmierczak, A. (2015). Climate change and the city: Building capacity for urban adaptation. Progress in Planning, 95, 1-66.

Chen, J., Gao, J., \& Chen, W. (2016). Urban land expansion and the transitional mechanisms in Nanjing, China. Habitat International, 53, 274-283.

Deal, B., Hewings, G., Kim, J., \& Kim, Y. (2013). Complex urban systems integration: The LEAM experiences in coupling economic, land use, and transportation models in Chicago, IL. In M. Fischer, J. Thill, J. van Dijk, \& H. Westlund (Eds.), Advances in spatial science (Vol. 74; pp. 107-131). Springer.

Deal, B., \& Pallathucheril, V. (2008). Simulating regional futures: The Land-Use Evolution and impact Assessment Model (LEAM). In R. Brail (Ed.), Planning support systems for cities and regions (pp. 61-84). Lincoln Institute of Land Policy.

Deilami, K., Kamruzzaman, M., \& Liu, Y. (2018). Urban heat island effect: A systematic review of spatio- temporal factors, data, methods, and mitigation measures. International Journal of Applied Earth Observation and Geoinformation, 67, 30-42.

Dolman, N. (2021). Integration of water management and urban design for climate resilient cities. In R. de Graaf (Ed.), Climate resilient urban areas: Governance, design and development in coastal delta cities (pp. 21-43). Palgrave Macmillan.

Fu, X., Gomaa, M., Deng, Y., \& Peng, Z.-R. (2017). Adaptation planning for sea level rise: A study of US coastal cities. Journal of Environmental Planning and Management, 60(2), 249-265.

Gu, C., Hu, L., Zhang, X., Wang, X., \& Guo, J. (2011). Climate change and urbanization in the Yangtze River Delta. Habitat International, 35(4), 544-552.

Han, G., Yuang, J., \& Li, K. (2016). Research on the urban vulnerability in Lanzhou. Journal of Arid Land Resources and Environment, 30(11), 70-76.

Hay, G. J., Hemachandran, B., Chen, G., \& Kyle, C. D. (2010). HEAT-Home energy assessment technologies: A web 2.0 residential waste heat analysis using geobia and airborne thermal imagery. GIM International, 24(3), 1-3.

Hofstad, H., \& Torfing, J. (2017). Towards a climateresilient city: Collaborative innovation for a 'green shift' in Oslo. In R. Álvarez Fernández, S. Zubelzu, \& R. Martínez (Eds.), Carbon footprint and the industrial life cycle (pp. 221-242). Springer.

Hong, W., Jiang, R., Yang, C., Zhang, F., Su, M., \& Liao, Q. (2016). Establishing an ecological vulnerability assessment indicator system for spatial recognition and management of ecologically vulnerable areas in highly urbanized regions: A case study of Shenzhen, China. Ecological Indicators, 69, 540-547.

Jabareen, Y. (2009). Building conceptual framework: Philosophy, definitions and procedure. International Journal of Qualitative Methods, 8(4), 49-62.

Jabareen, Y. (2013). Planning the resilient city: Concepts and strategies for coping with climate change and environmental risk. Cities, 31, 220-229.

Jafari, S., \& Zaredar, N. (2010). Land suitability analysis using multi-attribute decision making approach. International Journal of Environmental Science and Development, 1(5), 441-445.

Ji, B., Kong, J., \& Kong, S. Y. (2007). Main ecoenvironmental problems in the course of urbanization and ecological city construction in Nanjing. Journal of Modern Urban Research, 2007(5), 38-41.

Li, G., Cai, L., Chen, L., Chen, T., Zhang, X., \& Pan, Y. (2018). Relations of total electricity consumption to climate change in Nanjing. Energy Procedia, 152, 756-761.

Lomba-Fernández, C., Hernantes, J., \& Labaka, L. (2019). Guide for climate-resilient cities: An urban critical infrastructures approach. Sustainability, 11(17), Article 4727.

Meera, S. N., Balaji, V., Muthuraman, P., Sailaja, B., \& Dixit, S. (2012). Changing roles of agricultural extension: Harnessing information and communica- 
tion technology (ICT) for adapting to stresses envisaged under climate change. In B. Venkateswarlu, A. Shanker, C. Shanker, \& M. Maheswari (Eds.), Crop stress and its management: Perspectives and strategies (pp. 585-605). Springer.

Mejri, O., Menoni, S., Matias, K., \& Aminoltaheri, N. (2017). Crisis information to support spatial planning in post disaster recovery. International Journal of Disaster Risk Reduction, 22, 46-61.

National Bureau of Statistics of China. (2020). Zhongguo zhuyao chengshi niandu zhibiao shuju [Annual index data of major cities in China]. https://data.stats.gov. $\mathrm{cn} /$ easyquery.htm?cn=E0105

National Earth System Science Data Infrastructure, \& National Science and Technology Infrastructure of China. (2020). Nanjing shi 1: 25 wan ziyuan huanjing baohu shuju [Nanjing 1: 250.000 resource and environmental protection data]. http://nnu. geodata.cn:8008/data/datadetails.html?dataguid= $122473169935001 \&$ docid $=171$

Navarra, D., \& Bianchi, C. (2013). Territorial governance, e-government and sustainable development policy: A system dynamics approach. In M. A. Wimmer, M. Janssen, \& H. J. Scholl (Eds.), Electronic Government. EGOV 2013. Lecture Notes in Computer Science (Vol. 8074, pp. 14-25). Springer.

Pan, H., Deal, B., Destouni, G., Zhang, Y., \& Kalantari, Z. (2018). Sociohydrology modeling for complex urban environments in support of integrated land and water resource management practices. Land Degradation \& Development, 29(10), 3639-3652.

Pan, H., Page, J., Zhang, L., Chen, S., Cong, C., Destouni, G., Kalantari, Z., \& Deal, B. (2019). Using comparative socio-ecological modeling to support climate action planning (CAP). Journal of Cleaner Production, 232, 30-42.

Pan, H., Page, J., Zhang, L., Cong, C., \& Kalantari, Z. (2020). Understanding interactions between urban development policies and GHG emissions: A case study in Stockholm Region. Ambio, 49, 1313-1327.

Qi, Y., \& Gu, C. (2011). Discussion on urban planning for responding to climate change in rapidly urbanizing areas: Taking Nanjing as an example. Human Geography, 26(5), 54-59.

Qiao, Q., Gao, J., Wang, W., Tian, M., \& Lu, S. (2008). Method and application of ecological frangibility assessment. Research of Environmental Sciences,
21(5), 117-123.

Rahman, M. R., Shi, Z. H., Chongfa, C., \& Dun, Z. (2015). Assessing soil erosion hazard-A raster based GIS approach with spatial principal component analysis (SPCA). Earth Science Informatics, 8, 853-865.

Roberts, D., Boon, R., Diederichs, N., Douwes, E., Govender, N., Mcinnes, A., Mclean, C., O'Donoghue, S., \& Spires, M. (2011). Exploring ecosystem-based adaptation in Durban, South Africa: "Learning-by-doing" at the local government coal face. Environment and Urbanization, 24(1), 167-195.

Song, G., Chen, Y., Tian, M., Lv, S., Zhang, S., \& Liu, S. (2010). The ecological vulnerability evaluation in Southwestern Mountain Region of China based on GIS and AHP method. Procedia Environmental Sciences, 2, 465-475.

Verweij, P., Cormont, A., Eupen, M., Winograd, M., \& Hardoy, J. (2020). Participatory modeling with QUICKScan to shape sustainable urban development. Frontiers in Environmental Science, 8, 266.

Wamsler, C., Brink, E., \& Rivera, C. (2013). Planning for climate change in urban areas: From theory to practice. Journal of Cleaner Production, 50(1), 68-81.

Wan, Z., Wang, Z., Dong, L., Wang, Y., Chen, D., Li, X., $\& \mathrm{Xu}, \mathrm{S}$. (2006). Ecosystem sensitivity assessment of Liaoning Province. Chinese Journal of Ecology, 25(6), 677-681.

Wardekker, A., Wilk, B., Brown, V., Uittenbroek, C., Mees, H., Driessen, P., Wassen, M., Molenaar, A., Walda, J., \& Runhaar, H. (2020). A diagnostic tool for supporting policymaking on urban resilience. Cities, 101, Article 102691.

Yangtze River Delta Science Data Centre. (2019). Nanjing shi tudi liyong ji chengzhen yongdi jiegou fenbu shuju [Data of land use and urban land use structure distribution in Nanjing]. http://www.geodata.cn/ data/datadetails.html?dataguid $=238990791979153$ \&docid $=9126$

Zhang, L., Cong, C., Pan, H., Cai, Z., Cvetkovic, V., \& Deal, B. (2021). Socioecological informed comparative modeling to promote sustainable urban policy transitions: Case study in Chicago and Stockholm. Journal of Cleaner Production, 281, Article 125050.

Zhang, X., Wang, L., Fu, X., Li, H., \& Xu, C. (2017). Ecological vulnerability assessment based on PSSR in Yellow River Delta. Journal of Cleaner Production, 167, 1106-1111.

\section{About the Authors}

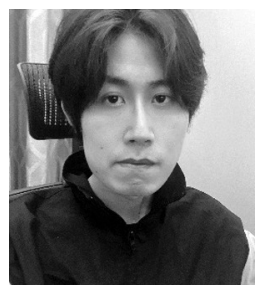

Zipan Cai is a PhD student in the Department of Sustainable Development, Environmental Science and Engineering (SEED) at the KTH Royal Institute of Technology, Sweden. His research interests include urban spatial planning, spatial dynamic modelling, planning support system, and smart city studies. He has over 10 years of experience in the field of GIS and related professional skills. His current research focuses on decision support for urban planning. 


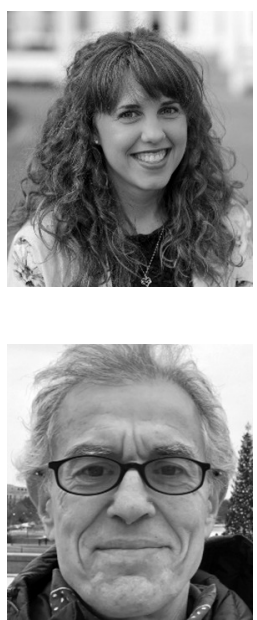

Jessica Page is a PhD student at the Department of Physical Geography, Stockholm University, Sweden. Her focus is on urban and regional planning, in particular on using technology and planning support systems to further sustainability goals in cities through the study and modelling of the interactions between urban and sub-urban social systems with various ecological systems, ecosystem services, and water-climate interactions.

Vladimir Cvetkovic (PhD) is a Full Professor in Water System Engineering at the Department of Sustainable Development, Environmental Science and Engineering (SEED) at the KTH Royal Institute of Technology, Sweden. His research has been mostly focused on water resources involving theoretical and experimental studies. Since 2015, he has been coordinating and working on projects related to urban systems, particularly the socio-technical development toward sustainable smart cities. 